\title{
Increasing grass hay inclusion level on weaned dairy calf growth, intake, digestibility, and ruminal fermentation
}

\author{
L. K. Mitchell and A. J. Heinrichs* \\ Department of Animal Science, The Pennsylvania State University, University Park 16802
}

\begin{abstract}
The objective was to determine effects of increasing grass hay (GH) inclusion level on weaned dairy calf growth, intake, digestibility, and ruminal fermentation. Holstein calves $(\mathrm{n}=45)$ were randomly assigned to 1 of 3 total mixed rations with increasing GH [10, 17.5, or $25 \%$ on a dry matter (DM) basis; LGH, MGH, or HGH, respectively]. Calves were weaned at 6 wk of age, housed individually, and studied from 7 to $16 \mathrm{wk}$ of age. Rations, consisting of texturized calf starter $(20 \%$ crude protein) and coarsely chopped GH, were offered ad libitum as separate components from 7 to 9 wk of age. After 9 wk, feed was offered as a total mixed ration containing the assigned level of GH and fed according to the clean bunk feeding strategy as a means of limiting refusals. Initial 9-wk body weight was $81.6 \pm 9 \mathrm{~kg}$ (mean \pm standard deviation). Intake and growth were measured weekly. Blood samples were collected at 9, $10,12,14$, and 16 wk of age for analysis of plasma glucose and $\beta$-hydroxybutyrate. Total fecal collection (12 calves; 4 per treatment) was conducted at 11 and $15 \mathrm{wk}$ of age for $4 \mathrm{~d}$ consecutively. Rumen samples were collected over the final $24 \mathrm{~h}$ of each fecal collection period to evaluate $\mathrm{pH}$ and volatile fatty acid profile. Feeds and feces were evaluated for DM, neutral detergent fiber, acid detergent fiber, and starch to estimate total-tract digestibility. Intake and weight gain were analyzed from 7 to 9 wk and 9 to $16 \mathrm{wk}$, representing pretreatment and treatment periods. No differences were observed between treatments from 7 to 9 wk. However, differences were found from 9 to 16 wk. Final body weight, average daily gain, DM intake, and metabolizable energy intake all decreased with increased GH. However, skeletal frame measurements did not vary between treatments. Plasma $\beta$-hydroxybutyrate tended to decrease with increased GH. No differences were observed in DM or starch digestibility, but neutral detergent
\end{abstract}

Received March 26, 2020.

Accepted May 12, 2020.

*Corresponding author: ajh@psu.edu fiber and acid detergent fiber digestibility increased with increased GH. Mean rumen $\mathrm{pH}$ and total volatile fatty acid did not change with increasing GH inclusion; however, there was an interaction with time indicating that ruminal fermentation patterns throughout the day were different for calves offered MGH and HGH versus those offered LGH. These results indicate that feeding levels of $\mathrm{GH}>10 \%$ reduce growth and intake before 16 wk and alter ruminal fermentation patterns.

Key words: digestibility, grass hay, weaned calf

\section{INTRODUCTION}

Providing forage during the preweaning phase has been discussed (Suarez-Mena et al., 2016) due to the well-known role that butyric acid by way of concentrate fermentation plays in driving rumen development (Stobo et al., 1966; Davis and Drackley, 1998). Quigley et al. (2019) showed that $15 \mathrm{~kg}$ of cumulative NFC intake was the point that indicated proper ruminal development, as it was at that level that calves exhibited maximal digestion of nutrients in calf starter and were therefore able to extract the greatest amount of energy from their diet. Several factors affect the age at which calves meet the goal of $15 \mathrm{~kg}$ of cumulative NFC intake, including health, milk feeding program, and starter composition, but under most circumstances this intake goal should be reached by 2 to 3 wk after weaning. Once this goal is met, there is little debate that forage should be offered, but the ideal level of forage that should be offered to weaned calves is unclear.

Replacement heifers represent the second or third largest expense to dairy farms (Heinrichs et al., 2013). Incorporation of increased levels of forage into diets of recently weaned calves, if appropriate, presents an opportunity to reduce ration costs and therefore reduce the cost of raising replacements. However, increased forage feeding cannot come at the expense of growth rates that will impair the animal's ability to meet weight and growth goals for breeding and freshening. During the immediate postweaning phase of 8 to $16 \mathrm{wk}$ of age, rumen volume is expanding and may limit the level of forage that can be offered to these animals, which will 
allow them to consume enough energy to meet growth goals.

Hill et al. (2010) found that feeding increased levels of chopped straw $(0,3,6$, and $9 \%)$, alfalfa hay $(0,5$, 10 , and $15 \%)$, or $\mathrm{GH}(0,3,6$, and $9 \%)$ reduced $\mathrm{ADG}$ in calves age 8 to 16 wk. However, the ADG accomplished when feeding the maximum amount of forage in these 3 trials were $890,1,070$, and $1,090 \mathrm{~g} / \mathrm{d}$ for straw, alfalfa hay, and GH, respectively. Hill et al. (2008, 2009) observed ADG of 980 and $900 \mathrm{~g} / \mathrm{d}$ when calves were fed $15 \%$ GH from 8 to 12 wk of age. Zanton and Heinrichs (2005) observed a prepubertal growth rate of $800 \mathrm{~g} / \mathrm{d}$ for heifers between 150 and $320 \mathrm{~kg}$ of BW allowed for maximal first-lactation milk production. The reported ADG by Hill et al. (2008, 2009, 2010) met or exceeded that which is necessary for calves before $150 \mathrm{~kg}$ of BW to accomplish desirable growth goals at breeding if grown according to the recommendations of Zanton and Heinrichs (2005) after calves reach $150 \mathrm{~kg}$ of BW. These results indicate an opportunity to increase the inclusion of forage, while still accomplishing desirable growth rates.

Qamar et al. (2019) maintained growth rates $\geq 1,000$ $\mathrm{g} / \mathrm{d}$ when feeding as much as $26 \%$ Rhodes grass hay to calves from 8 to 12 wk. Similarly, Van Ackeren et al. (2009) accomplished growth rates exceeding 1,000 $\mathrm{g} / \mathrm{d}$ when offering a diet containing $28 \%$ of a grass and alfalfa hay blend to calves from 8 to 15 wk. In a study using alfalfa hay as the sole forage and including it at $25 \%$, Nemati et al. (2016) observed growth rates of $900 \mathrm{~g} / \mathrm{d}$ for calves from 7 to $10 \mathrm{wk}$. All of these studies accomplished desirable growth rates, despite feeding substantially increased levels of forage. However, these studies fed forage mixed with entirely ground (Nemati et al., 2016; Qamar et al., 2019) or a combination of ground and pelleted concentrates (Van Ackeren et al., 2009), which has been shown to have positive benefits on intake and growth versus feeding forage with a texturized concentrate (Imani et al., 2017), as was done in the Hill et al. $(2008,2009,2010)$ studies. It is also worth noting the largest geometric mean particle size that forage was chopped in the discussed studies was $3 \mathrm{~mm}$ (Nemati et al., 2016) and the greatest amount of forage retained on sieves larger than $16 \mathrm{~mm}$ was 9.1\% (Hill et al., 2008). Therefore, forage used in these studies was very finely chopped, which would be expected to at least partially negate the effect of forage on gut fill (Allen, 1996), thus allowing animals in these studies to consume enough DM to support desirable growth rates. Digestibility would also be expected to be reduced by increased forage inclusion, which would increase gut fill and decrease DMI. Alfalfa hay is also well known to be more digestible than grass hay (Allen, 2000), which would allow for increased usage of alfalfa hay compared with grass hay while still accomplishing desirable growth rates.

It is clear that weaned calves are able to accomplish recommended growth rates when fed as much as 15 or $28 \%$ of a finely chopped forage along with texturized or ground concentrates, respectively. However, no data are available investigating the effects of feeding increased levels of long or coarsely chopped grass hay to calves from 8 to 16 wk. Feeding increased levels of coarsely chopped forage would reduce the time needed for forage processing as well as the ration cost. The objective of this study was to determine the effects of feeding increased levels of coarsely chopped grass hay on growth, intake, digestibility, and ruminal fermentation parameters of weaned dairy calves. We hypothesized that increasing grass hay level would decrease intake and growth, but recommended growth rates may still be accomplished.

\section{MATERIALS AND METHODS}

\section{Animals and Treatments}

Procedures used in this study were reviewed and approved by The Pennsylvania State University Institutional Animal Care and Use Committee (IACUC \#47347). Forty-five Holstein calves (33 female, 12 male) were randomly assigned by sex to a treatment and studied from 7 to 16 wk of age. Calves were born over the course of $\sim 2$ mo so they were admitted to the study on a rolling basis as they reached $7 \mathrm{wk}$ of age. Treatments consisted of feeding a TMR with increasing levels of grass hay $(10,17.5$, or $25 \%$ on a DM basis; LGH, MGH, or HGH, respectively). The grass hay was coarsely chopped using a Roto Grind tub grinder and particle size distribution was determined using the Penn State Particle Separator $(63.3 \pm 6.6 \%$ larger than $19 \mathrm{~mm}, 11.2 \pm 2.5 \%$ between 8 and $19 \mathrm{~mm}, 8.5 \pm 1.5 \%$ between 4 and $8 \mathrm{~mm}$, and $16.0 \pm 3.4 \%$ smaller than 4 $\mathrm{mm})$.

Calves were offered $6 \mathrm{~L} / \mathrm{d}$ of pasteurized whole milk through $5 \mathrm{wk}$ and $3 \mathrm{~L} / \mathrm{d}$ until weaning at $6 \mathrm{wk}$. Texturized calf starter (East Gate Feed \& Grain, Reedsville, PA; Table 1) and water were offered ad libitum from $3 \mathrm{~d}$ of age. Coarsely chopped grass hay was introduced to calves and fed separately from the texturized calf starter for the pretreatment period from 7 to $9 \mathrm{wk}$. At 9 wk, calves were abruptly converted to their assigned TMR, consisting of grass hay and ground concentrates (Table 1), and fed according to clean bunk feeding strategy. This feeding strategy involves adjusting feed offered each day such that refusals may be limited but intakes still meet or exceed that of animals fed ad libitum (Pritchard and Bruns, 2003). 
Table 1. Ingredient and chemical composition of diets and feedstuffs

\begin{tabular}{|c|c|c|c|c|c|}
\hline \multirow[b]{2}{*}{ Item $^{1}$} & \multicolumn{3}{|c|}{$\operatorname{Diet}^{2}$} & \multirow{2}{*}{$\begin{array}{c}\text { Calf } \\
\text { starter }^{3}\end{array}$} & \multirow{2}{*}{$\begin{array}{c}\text { Grass } \\
\text { hay }\end{array}$} \\
\hline & LGH & MGH & $\mathrm{HGH}$ & & \\
\hline \multicolumn{6}{|l|}{ Ingredient } \\
\hline Grass hay & 10.0 & 17.5 & 25.0 & - & - \\
\hline Ground corn & 64.8 & 58.5 & 52.3 & - & - \\
\hline Soybean meal & 18.5 & 17.3 & 16.0 & - & - \\
\hline Molasses & 5.0 & 5.0 & 5.0 & - & - \\
\hline Mineral mix & 1.7 & 1.7 & 1.7 & - & - \\
\hline \multicolumn{6}{|c|}{ Chemical composition } \\
\hline DM (\% as fed) & 89.0 & 88.9 & 88.8 & 90.4 & 89.3 \\
\hline $\mathrm{CP}$ & 15.9 & 16.0 & 16.1 & 25.0 & 16.0 \\
\hline NDF & 14.6 & 19.1 & 22.9 & 19.9 & $66.2^{4}$ \\
\hline $\mathrm{ADF}$ & 6.1 & 8.5 & 10.5 & 7.7 & $34.7^{4}$ \\
\hline Starch & 50.0 & 45.3 & 40.6 & 28.5 & 1.0 \\
\hline Ash & 5.3 & 5.7 & 6.0 & 7.8 & 7.9 \\
\hline $\mathrm{Ca}$ & 0.4 & 0.4 & 0.5 & 1.2 & 0.6 \\
\hline $\mathrm{P}$ & 0.4 & 0.4 & 0.4 & 0.7 & 0.3 \\
\hline $\mathrm{ME}^{5}(\mathrm{Mcal} / \mathrm{kg})$ & 3.0 & 3.0 & 2.9 & 3.0 & 2.2 \\
\hline \multicolumn{6}{|c|}{$\overline{{ }^{1} \% \text { of DM, unless otherwise noted. }}$} \\
\hline \multicolumn{6}{|c|}{${ }^{2}$ Low, medium, or high grass hay inclusion level (LGH, MGH, and HGH, respectively). } \\
\hline \multirow{2}{*}{\multicolumn{6}{|c|}{$\begin{array}{l}{ }^{3} \text { Offered to } 9 \text { wk of age. Ingredients: roasted flaked corn }(18.6 \%) \text {, whole oats }(2.5 \%), 20 \% \text { calf pellet }(72.1 \%) \text {, } \\
\text { liquid molasses }(6.3 \%) \text {, soybean oil }(0.5 \%) \text {, calf flavor }(0.1 \%) \text {, and rumensin }(0.03 \%) \text {. } \\
{ }^{4} \text { Standard deviation for NDF } \pm 4.3 \text { and } \mathrm{ADF} \pm 2.9 \text {. }\end{array}$}} \\
\hline & & & & & \\
\hline \multicolumn{6}{|c|}{${ }^{5}$ Calculated according to the NRC (2001) equation: } \\
\hline
\end{tabular}

Calves were housed individually for the duration of the study and bedded with shavings. Calves were moved from outside hutches at 9 wk to a mechanically ventilated barn, where they were housed for the remainder of the trial. Twelve male calves $(n=4$ per treatment) were surgically fitted with a 3 -cm rumen cannula at $4 \pm 2.5$ wk of age. Cannulated animals were moved to a mechanically ventilated tiestall barn at 11 and 15 wk of age where total fecal collection occurred for $4 \mathrm{~d}$ and rumen sampling occurred over the last $24 \mathrm{~h}$ of each total collection period.

\section{Sample Collection and Analysis}

Body weight, hip width, hip height, withers height, and heart girth were measured weekly starting at the beginning of the pretreatment period (7 wk) and continuing through 16 wk of age. Feed was offered at 0800 $\mathrm{h}$ each day. Refusals and feedstuffs were collected once per week and dried in a forced-air oven at $55^{\circ} \mathrm{C}$ for 48 $\mathrm{h}$ to determine DM (AOAC International, 2000). Dried weekly refusals were subtracted from weekly DM offered to determine daily DMI. Dried refusals and feedstuffs were ground through a Wiley mill (Wiley mill, Arthur H. Thomas, Philadelphia, PA) using a 1-mm screen and stored for further analysis.

Fecal collection took place for 4 consecutive days at 11 and 15 wk of age. Total feces were collected into custom-made polyester bags held to the back end of the animal by straps from custom harnesses. The bags were emptied twice daily into sealed collection containers. Subsamples were collected for each day and composited for each calf at each age. The composited sample was dried in a forced-air oven at $55^{\circ} \mathrm{C}$ for $72 \mathrm{~h}$ (AOAC International, 2000). Dried fecal samples were ground through a Wiley mill using a 1-mm screen and stored for further analysis.

Dried and ground refusals, feedstuffs, and feces were analyzed for DM, and then NDF and ADF sequentially with an Ankom ${ }^{200}$ fiber analyzer (Ankom Technology Corp., Fairport, NY) and starch. According to the procedures of Van Soest et al. (1991), NDF content was determined with the use of heat-stable $\alpha$-amylase and sodium sulfite. A modified method of Hall (2009) was used to determine starch content. Feedstuffs were sent to Cumberland Valley Analytical Services Inc. (Waynesboro, PA) for further analysis of $\mathrm{CP}$, ash, $\mathrm{Ca}, \mathrm{P}$, and TDN according to their procedures (Cumberland Valley Analytical Services, 2011). The Ohio Agricultural Research and Development Center summative energy equation of Weiss (1998) was used to calculate TDN. Metabolizable energy of feedstuffs was estimated using TDN according to the NRC (2001) equation: $\mathrm{ME}=1.01 \times(0.04409 \times \mathrm{TDN})$ -0.45 .

Blood samples were collected via the jugular vein into sodium heparin-containing evacuated tubes (Vacutainer, Becton Dickinson, Franklin Lakes, NJ). Samples were collected, before feeding, at the beginning of the treatment period (9 wk) and then at 10, 12, 14, 
and 16 wk. After collection, samples were centrifuged at $4^{\circ} \mathrm{C}$ for $15 \mathrm{~min}$ at $1,500 \times \mathrm{g}$. Plasma was collected and stored at $-20^{\circ} \mathrm{C}$ until being analyzed for glucose (PGO Enzyme Procedure No. P 7119, Sigma-Aldrich, St. Louis, MO) and BHB (Procedure No. 2440, Stanbio Laboratory, Boerne, TX).

Rumen fluid samples were collected during the final $24 \mathrm{~h}$ of each fecal collection period at $0,1,2,4,6,8,12$, 16,20 , and $22 \mathrm{~h}$ postfeeding. Samples were collected via a plastic hose with a metal suction strainer (Precision Machine Company Inc., Lincoln, NE) attached to one end and a $60-\mathrm{mL}$ syringe attached to the other. The device was inserted into the ventral sac of the rumen via the cannula opening for fluid collection. The ventral sac was targeted due to the small size of the cannula opening not allowing for accurate sampling from multiple locations within the rumen. Approximately $50 \mathrm{~mL}$ of rumen fluid was collected at each time point and tested immediately for $\mathrm{pH}$ with a handheld portable $\mathrm{pH}$ meter (pH meter, model M90, Corning Inc., Corning, NY). Duplicate 5 -mL samples of rumen fluid were saved in 15 -mL tubes containing $1 \mathrm{~mL}$ of $0.6 \%$ 2-ethylbutyric acid and $1 \mathrm{~mL}$ of $25 \%$ metaphosphoric acid and stored at $-20^{\circ} \mathrm{C}$ until analysis for VFA content (Yang and Varga, 1989).

Health of calves was monitored daily and fecal scores were assigned by trained personnel according to the CalfTrack system outlined by Lesmeister and Heinrichs (2004). Fecal scores were assigned as 1 through $5(1=$ firm to soft; $5=$ watery, mucus, bloody).

\section{Statistical Analysis}

Statistical analyses were conducted using SAS (version 9.4, SAS Institute Inc., Cary, NC). The MIXED procedure was used to analyze all variables, with the exception of average fecal score in which Proc GLIMMIX was used. Experimental design was randomized complete block as calves were blocked by sex and randomly assigned to treatments. Calf was the experimental unit as they were housed individually and measurements were taken and known for each animal. Body weight and frame measurements at 7 wk were analyzed and found to be not different. Initial and final BW and frame measurements, as determined at 9 and 16 wk of age, as well as days with fecal score $>1$ were evaluated with the fixed effect of treatment and the random block effect of sex. No differences or tendencies for differences were observed in DMI or ADG during the pretreatment period of 7 to 9 wk. However, initial BW at 9 wk did tend to differ between treatments and was therefore used as a covariate in the analysis of final BW, growth rate, intake, and feed efficiency variables. Initial frame measurements did not differ between treatments and were not used as covariates.

Intake and growth variables were evaluated for the pretreatment and treatment periods ( 7 to 9 wk and 9 to $16 \mathrm{wk}$, respectively) using an expanded model to include the repeated effect of age, interaction effect of treatment $\times$ age, and the random effects of calf and week of study. No differences were found for the pretreatment period. As a result of calves being admitted to the study on a rolling basis, week of study was included as a random variable to account for minor weather and forage variances throughout the course of the study. A first-order autoregressive $[\mathrm{AR}(1)]$ covariance matrix was applied as determined by Akaike's information criterion. Plasma metabolites were evaluated using the same model, but a spatial power covariance matrix was applied due to unevenly spaced sampling intervals. Average fecal score was evaluated with Proc GLIMMIX and with a Poisson distribution applied.

Twelve male calves were used for the evaluation of digestibility, rumen $\mathrm{pH}$, and VFA; thus, sex was removed from the model used to evaluate these variables. Digestibility and maximum and minimum $\mathrm{pH}$ were evaluated with the variance component covariance matrix applied as determined by Akaike's information criterion. Time and its interactions were included in the model to evaluate mean rumen $\mathrm{pH}$ and VFA variables. Due to unevenly spaced sampling intervals, a spatial power covariance matrix was applied in the analysis of mean rumen $\mathrm{pH}$ and VFA variables.

The slice option within SAS was used when appropriate to evaluate differences between treatment within an age and between ages within a treatment. Degrees of freedom were determined using Kenward-Roger approximation for all procedures. Data are reported as least squares means along with standard error and compared with the Tukey adjustment. Significant differences were declared at $P \leq 0.05$ and tendencies at $0.05<P \leq 0.10$.

\section{RESULTS AND DISCUSSION}

\section{Diets}

Ingredient and nutrient composition of the TMR, as well as the calf starter offered in the pretreatment period, and grass hay are presented in Table 1. Calves were offered calf starter alongside coarse chopped grass hay $(63.3 \pm 6.6 \%$ larger than $19 \mathrm{~mm}, 11.2 \pm 2.5 \%$ between 8 and $19 \mathrm{~mm}, 8.5 \pm 1.5 \%$ between 4 and $8 \mathrm{~mm}$, and $16.0 \pm 3.4 \%$ smaller than $4 \mathrm{~mm}$ ) in component fashion during the pretreatment period from 7 to $9 \mathrm{wk}$. At $9 \mathrm{wk}$ calves were converted to their assigned TMR. The grass 
hay was packaged in round bales and made from a second cutting comprised of primarily orchardgrass. Diets were designed to contain similar levels of CP. However, fiber and starch levels were expected to increase and decrease, respectively, because as grass hay inclusion increased, ground corn inclusion decreased. This was expected to lead to a decrease in energy for diets with increased levels of GH. However, due to the high energy content of the concentrate used in this experiment, energy content of the HGH ration exceeded the energy in rations used in other studies feeding comparable levels of forage (Nemati et al., 2016; Qamar et al., 2019) and was in line with the energy content of a $5 \%$ grass hay ration fed by Hill et al. (2009). Rations were made as energy dense as possible to counterbalance the expected decrease in DMI.

\section{Growth and Intake}

Growth and intake variables are presented in Table 2. Dry matter intake decreased with increased GH inclusion to the extent that calves offered HGH consumed $16 \%$ less DM than those offered LGH. Calves offered MGH tended to consume less DM than LGH but only numerically more than HGH. All treatments in the cur- rent study consumed at least $500 \mathrm{~g} / \mathrm{d}$ DM less than that reported by Hill et al. (2010) for calves from 8 to 16 wk offered a ration containing $9 \% \mathrm{GH}$. In comparison to diets offering elevated levels of GH to similar-age calves, those offered MGH had similar DMI to calves offered a diet containing $28 \%$ of an alfalfa and $\mathrm{GH}$ blend (van Ackeren et al., 2009), despite the MGH ration containing $10.5 \%$ less forage. The intake reported by van Ackeren et al. (2009) may have been elevated in part due to providing a blend of alfalfa and $\mathrm{GH}$ as opposed to only GH. Alfalfa has been demonstrated to be consumed at increased levels (Castells et al., 2012) and positively affected intake relative to other forages (Imani et al., 2017). However, the increased particle size of GH fed in the current study provides the most likely explanation for reduced DMI observed in our study versus others, as it would be expected to have had a greater effect on eating rate and gut fill, decreasing rate of digestion (Allen, 1996). These results would further seem to suggest that the increase in intake observed when feeding forage with ground versus texturized concentrates (Imani et al., 2017) is negated by the effect of forage particle size.

Dry matter intake as a \% of BW decreased with increasing GH inclusion. A similar effect was not observed

Table 2. Weight and frame measurements, growth, and intake of weaned dairy calves from 9 to 16 wk of age offered TMR containing $10 \%$ $(\mathrm{LGH}), 17.5 \%(\mathrm{MGH})$, or $25 \%$ grass hay $(\mathrm{HGH})$

\begin{tabular}{|c|c|c|c|c|c|c|c|}
\hline \multirow[b]{2}{*}{ Item } & \multicolumn{3}{|c|}{ Diet } & \multirow[b]{2}{*}{$\mathrm{SE}$} & \multicolumn{3}{|c|}{$P$-value } \\
\hline & LGH & MGH & $\mathrm{HGH}$ & & Diet & Age & Diet $\times$ age \\
\hline \multicolumn{8}{|l|}{ Weight and frame $^{1}$} \\
\hline Initial BW (kg) & 77.8 & 81.8 & 85.1 & 2.32 & 0.101 & - & - \\
\hline Final BW (kg) & $131.5^{\mathrm{a}}$ & $127^{\mathrm{ab}}$ & $121.3^{\mathrm{b}}$ & 4.09 & 0.008 & - & - \\
\hline Initial hip width (cm) & 21.3 & 21.7 & 21.7 & 0.29 & 0.513 & - & - \\
\hline Final hip width $(\mathrm{cm})$ & 26.1 & 26.2 & 26.0 & 0.62 & 0.881 & - & - \\
\hline Initial hip height $(\mathrm{cm})$ & 93.0 & 93.2 & 93.6 & 0.74 & 0.820 & - & - \\
\hline Final hip height $(\mathrm{cm})$ & 103.2 & 103.1 & 104.1 & 0.84 & 0.632 & - & - \\
\hline Initial withers height $(\mathrm{cm})$ & 88.8 & 89.2 & 90.3 & 0.71 & 0.340 & - & - \\
\hline Final withers height $(\mathrm{cm})$ & 99.6 & 99.5 & 100.4 & 0.82 & 0.701 & - & - \\
\hline Initial heart girth $(\mathrm{cm})$ & 97.7 & 98.9 & 99.7 & 0.88 & 0.286 & - & - \\
\hline Final heart girth $(\mathrm{cm})$ & 114.7 & 115.0 & 114.5 & 1.00 & 0.930 & - & - \\
\hline \multicolumn{8}{|l|}{ Growth $(\mathrm{kg} / \mathrm{d})$} \\
\hline $\mathrm{ADG}$ & $1.03^{\mathrm{a}}$ & $0.92^{\mathrm{ab}}$ & $0.80^{\mathrm{b}}$ & 0.08 & 0.001 & $<0.001$ & 0.164 \\
\hline $\mathrm{EBWG}^{2}$ & $0.91^{\mathrm{a}}$ & $0.80^{\mathrm{a}}$ & $0.65^{\mathrm{b}}$ & 0.08 & $<0.001$ & $<0.001$ & 0.043 \\
\hline \multicolumn{8}{|l|}{ Intake $(\mathrm{kg} / \mathrm{d})$} \\
\hline DM & $3.38^{\mathrm{a}}$ & $3.09^{\mathrm{ab}}$ & $2.85^{\mathrm{b}}$ & 0.22 & 0.002 & $<0.001$ & 0.610 \\
\hline Grain & $3.04^{\mathrm{a}}$ & $2.55^{\mathrm{b}}$ & $2.12^{\mathrm{c}}$ & 0.19 & $<0.001$ & $<0.001$ & 0.454 \\
\hline Grass hay & $0.34^{\mathrm{c}}$ & $0.54^{\mathrm{b}}$ & $0.73^{\mathrm{a}}$ & 0.03 & $<0.001$ & $<0.001$ & $<0.001$ \\
\hline DMI ( $\%$ of BW) & $3.10^{\mathrm{a}}$ & $2.89^{\mathrm{b}}$ & $2.80^{\mathrm{b}}$ & 0.15 & 0.004 & $<0.001$ & 0.245 \\
\hline NDF & $0.49^{c}$ & $0.59^{\mathrm{b}}$ & $0.67^{\mathrm{a}}$ & 0.04 & $<0.001$ & $<0.001$ & $<0.001$ \\
\hline NDF (\% of BW) & $0.45^{\mathrm{c}}$ & $0.54^{\mathrm{b}}$ & $0.65^{\mathrm{a}}$ & 0.02 & $<0.001$ & $<0.001$ & 0.003 \\
\hline $\mathrm{ME}^{3}(\mathrm{Mcal} / \mathrm{d})$ & $10.28^{\mathrm{a}}$ & $9.16^{\mathrm{b}}$ & $8.17^{\mathrm{c}}$ & 0.67 & $<0.001$ & $<0.001$ & 0.598 \\
\hline Feed efficiency ${ }^{4}(\mathrm{~kg} / \mathrm{kg})$ & 0.30 & 0.30 & 0.27 & 0.02 & 0.214 & $<0.001$ & 0.222 \\
\hline
\end{tabular}

\footnotetext{
${ }^{a-c}$ Means within a row with different superscripts differ at $P \leq 0.05$.

${ }^{1}$ Initial weight and frame measurements are at 9 wk of age. Initial BW was used as a covariate for final BW, growth, and intake variables.

${ }^{2}$ Empty BW gain was calculated according to equations given by Jahn and Chandler (1976).

${ }^{3} \mathrm{ME}$ intake was calculated by multiplying ME (Mcal $\left./ \mathrm{kg}\right)$ content of the ration by DMI $(\mathrm{kg} / \mathrm{d})$.

${ }^{4}$ Feed efficiency was calculated by dividing ADG by DMI.
} 

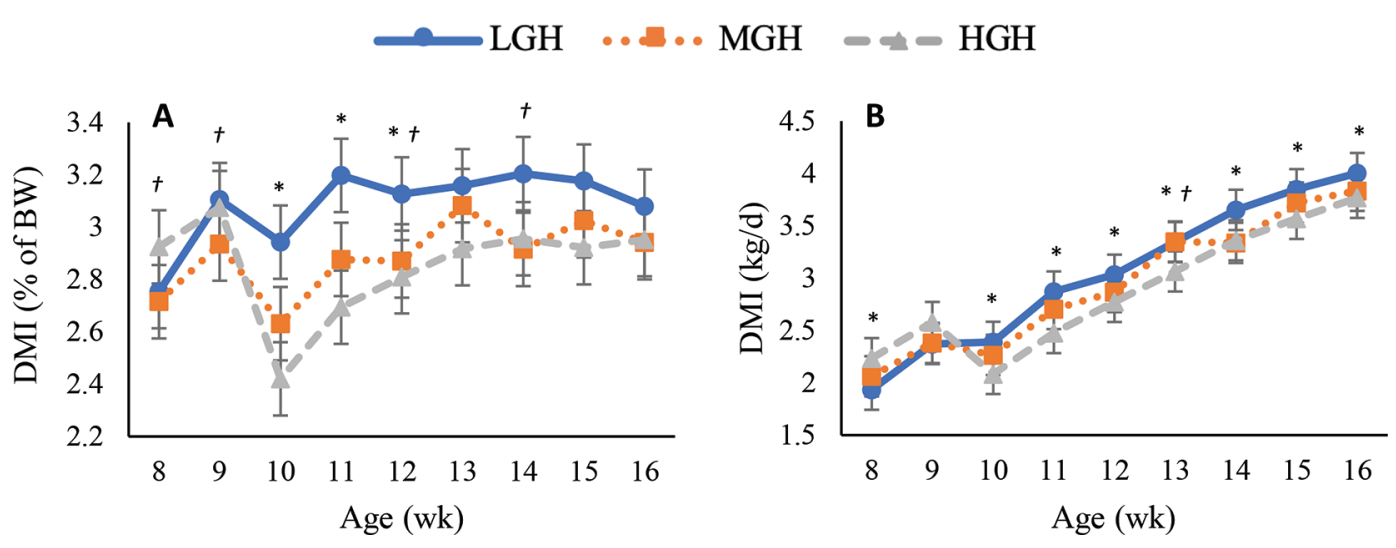

Figure 1. (A) Weekly DMI as \% of BW of weaned dairy calves offered TMR containing 10\% (LGH), 17.5\% (MGH), or 25\% grass hay (HGH). *Signifies differences between groups at that age $(P \leq 0.05 ; 10$ and 11 wk LGH $>$ MGH and HGH; 12 wk LGH $>$ HGH $)$. †Signifies trends between groups at that age $(0.05<P \leq 0.1 ; 8 \mathrm{wk} \mathrm{HGH}>$ MGH; 9, 12, and 14 wk LGH $>$ MGH). (B) Weekly DMI of weaned dairy calves offered TMR containing $10 \%(\mathrm{LGH}), 17.5 \%(\mathrm{MGH})$, or $25 \%$ grass hay $(\mathrm{HGH})$. ${ }^{*}$ Signifies differences between groups at that age $(P \leq$ $0.05 ; 8$ wk HGH $>$ LGH; 10 to $16 \mathrm{wk}$ LGH $>$ HGH; $14 \mathrm{wk} \mathrm{LGH}>$ MGH $)$. †Signifies trends between groups at that age $(0.05<P \leq 0.1 ; 13 \mathrm{wk}$ $\mathrm{MGH}>\mathrm{HGH})$. Error bars represent $\pm \mathrm{SE}$.

when increasing GH from 0 to 9\% (Hill et al., 2010), but reductions were observed when feeding 5 versus 15\% GH (Hill et al., 2009). Figure 1a shows that calves on different treatments had different responses to DMI as a $\%$ of $\mathrm{BW}$ during the first 2 to 3 wk after being converted to their respective TMR. Although this did not culminate in an interaction between diet and age, it does indicate that calves offered increased levels of GH required additional time to adapt to these ration changes. This is evidenced by the fact that calves offered LGH increased DMI as a \% of BW from 10 to 11 wk but did not change from 11 to $16 \mathrm{wk}$, whereas those offered MGH and HGH increased from 10 to 13 and 14 wk, respectively, before leveling off for the remainder of the study. These results indicate that increasing GH inclusion may affect weaned calves' ability to adapt to the ration, especially when rations contain levels of GH $>10 \%$ and when it is coarsely chopped.

Increasing GH inclusion resulted in decreases and increases to grain and GH intake, respectively, regardless of effects on DMI. Calves offered LGH consumed the most grain but the least GH, whereas those offered HGH consumed the least grain but the most GH. The MGH treatment exhibited intermediate intakes of grain and $\mathrm{GH}$ relative to $\mathrm{LGH}$ and $\mathrm{HGH}$. These results were expected and have been observed by others (Hill et al., $2008,2009)$. There was an interaction effect of diet by age on GH intake. This interaction was likely due to GH intake increasing by 420 versus $180 \mathrm{~g}$ from 9 to 16 wk for HGH and LGH, respectively. These differences in GH intake led to similar differences in NDF intake and NDF intake as a \% of BW as GH inclusion level increased. Age effects observed for NDF intake as a $\%$ of BW were similar to those seen for DMI as a $\%$ of
BW, as NDF intake gradually increased until 11, 13, or 14 wk of age for $\mathrm{LGH}, \mathrm{MGH}$, and $\mathrm{HGH}$, respectively. However, none of these treatment groups approached the $1 \%$ NDF intake as a $\%$ of BW observed by Hoffman et al. (2008), though it should be noted heifers in that trial were older and larger than in the current study as heifers started that study around 4 mo of age and 163 $\mathrm{kg}$. Hill et al. (2008) reported 0.6\% NDF intake as a \% of BW when feeding $15 \% \mathrm{GH}$ to calves from 8 to $12 \mathrm{wk}$, though how or if it changed with age was not presented.

Metabolizable energy intake also declined with increasing GH inclusion. This was expected due to the reduction in DMI and differences in the composition of the DM consumed. As a result of the reductions in DM and ME intake, ADG and empty BW gain (EBWG) declined as GH inclusion increased. Furthermore, calves offered MGH tended to have increased ADG compared with HGH but did not differ from LGH, though MGH tended to have reduced EBWG compared with LGH. Average daily gain of calves offered LGH and MGH are similar to ADG reported by Hill et al. (2008, 2009, 2010) of $1,090,900$, and $980 \mathrm{~g} / \mathrm{d}$ for calves offered 9,15 , and $15 \% \mathrm{GH}$, respectively. Calves in this trial offered HGH did not accomplish desirable ADG and seemed to be especially affected by gut fill as observed by the decrease in EBWG compared with MGH. Despite the decrease observed in ADG, feed efficiency was only numerically less for $\mathrm{HGH}$ and did not statistically differ between the treatments.

Weekly ADG and EBWG showed that all treatment groups in the current study had depressed ADG and EBWG during the first week after being offered their respective TMR. However, HGH exhibited the greatest struggle in adapting to the diet as they did not ac- 
Table 3. Plasma metabolites of weaned dairy calves from 9 to 16 wk of age offered TMR containing $10 \%$ $(\mathrm{LGH}), 17.5 \%(\mathrm{MGH})$, or $25 \%$ grass hay $(\mathrm{HGH})$

\begin{tabular}{|c|c|c|c|c|c|c|c|}
\hline \multirow{2}{*}{$\begin{array}{l}\text { Item } \\
(\mathrm{mg} / \mathrm{dL})\end{array}$} & \multicolumn{3}{|c|}{ Diet } & \multirow[b]{2}{*}{$\mathrm{SE}$} & \multicolumn{3}{|c|}{$P$-value } \\
\hline & LGH & MGH & $\mathrm{HGH}$ & & Diet & Age & Diet $\times$ age \\
\hline Glucose & 73.53 & 74.58 & 72.64 & 3.06 & 0.531 & 0.142 & 0.058 \\
\hline BHB & 2.27 & 2.04 & 2.02 & 0.19 & 0.116 & 0.134 & 0.842 \\
\hline
\end{tabular}

complish ADG $>900 \mathrm{~g} / \mathrm{d}$ until 13 wk of age, whereas LGH and MGH accomplished ADG >1,080 and 950 $\mathrm{g} / \mathrm{d}$, respectively, at just $11 \mathrm{wk}$ of age and were able to maintain those growth rates through the end of the study. These results are likely due to calves offered greater levels of $\mathrm{GH}$ being more affected by gut fill and perhaps rates of passage. These aspects that affect intake and growth affected the calves during the transition to feeding a TMR. Figure $1 \mathrm{~b}$ shows that calves offered LGH and MGH did not change their DMI during transition to TMR from 9 to 10 wk but afterward increased each week until the completion of the study. Calves offered HGH decreased their DMI by $500 \mathrm{~g} / \mathrm{d}$ during the transition to TMR from 9 to $10 \mathrm{wk}$ and increased weekly thereafter but did not exceed their DMI from 9 wk until $12 \mathrm{wk}$. Although calves on the different treatments had different DMI responses around the time of being converted to a TMR, this did not result in a diet by age interaction. The decrease in DMI along with the fact that the ration being consumed was less digestible due to the high content of GH explains why calves offered HGH had reduced ADG at the initiation of the study. Inclusion of $17.5 \%$ of coarsely chopped GH in diets appears to be the upper limit for calves before 3 mo of age.

Initial BW tended to differ at $9 \mathrm{wk}$, but initial skeletal frame measurements did not differ between treatments. However, the differences in ADG lead to differences in final BW. Final BW decreased with increasing GH. Interestingly, final frame measurements did not differ between the treatments, despite differences in weight gain. Based on population studies, calves in this trial had high structural growth (Heinrichs and Losinger, 1998). In comparison to more recent studies, calves in this trial had comparable frame growth to those recorded by Aragona et al. (2020) and Dennis et al. (2018).

\section{Plasma Metabolites}

Plasma glucose and BHB levels are reported in Table 3 . There were no differences in plasma glucose between the treatment groups. However, there was a diet by age tendency for interaction on plasma glucose. Calves offered LGH and MGH had increases in plasma glucose from 9 to $10 \mathrm{wk}$, which were then maintained for the remainder of the study. Calves offered HGHH had a decrease in plasma glucose from 9 to $10 \mathrm{wk}$ and it remained depressed until increasing at 14 and 16 wk. It is likely that the different responses over time were due to the starch content of the TMR and effect of the diet transition on DMI. There was a tendency for plasma BHB to decline as GH increased. These results differ with those that have recorded elevated BHB for calves offered $25 \%$ alfalfa hay versus those offered 12.5 or $0 \%$ at $10 \mathrm{wk}$ (Nemati et al., 2015, 2016) and those that recorded no change when diets were offered with or without forage (Mojahedi et al., 2018). However, when the effect of these diets on intake is considered, similar effects were observed. In the current study, the decline in BHB coincided with a decline in DMI. In the studies by Nemati et al. $(2015,2016)$ and Mojahedi et al. (2018), similar observations were made, as calves with no change or decreases in DMI exhibited no change or decreases in plasma BHB.

\section{Health}

The average fecal score tended to differ between the treatment groups $(1.19,1.24$, and 1.10 for LGH, MGH, and HGH, respectively), and the number of days with a fecal score $>1$ also tended to be different $(8.5,10.0$, and 4.3 for LGH, MGH, and HGH, respectively). The reasons for these tendencies are not readily apparent, are physiologically very small, and are likely not important. It can be concluded that calves in this study were quite healthy.

\section{Digestibility}

Nutrient digestibility is reported in Table 4. Digestibility of DM was not different between the treatments, despite those on HGH consuming a ration with increased NDF and decreased starch. The difference in nutrient profiles between the LGH and HGH rations would have been expected to reduce DM digestibility as has been observed by others feeding similar-age animals (Dennis et al., 2018) or animals at approximately 1 yr of age (Lascano and Heinrichs, 2011). The lack of observed 
Table 4. Nutrient digestibility of weaned dairy calves at 11 and 15 wk of age offered TMR containing $10 \%$ (LGH), $17.5 \%(\mathrm{MGH})$, or $25 \%$ grass hay $(\mathrm{HGH})$

\begin{tabular}{|c|c|c|c|c|c|c|c|c|}
\hline \multirow{2}{*}{$\begin{array}{l}\text { Digestibility } \\
(\%)\end{array}$} & \multirow{2}{*}{$\begin{array}{l}\text { Age } \\
\text { (wk) }\end{array}$} & \multicolumn{3}{|c|}{ Diet } & \multirow[b]{2}{*}{$\mathrm{SE}$} & \multicolumn{3}{|c|}{$P$-value } \\
\hline & & LGH & MGH & $\mathrm{HGH}$ & & Diet & Age & Diet $\times$ age \\
\hline \multirow[t]{2}{*}{$\mathrm{DM}$} & 11 & 76.0 & 75.6 & 76.7 & 1.77 & 0.521 & 0.598 & 0.217 \\
\hline & 15 & 77.2 & 76.1 & 73.4 & & & & \\
\hline \multirow[t]{2}{*}{ NDF } & 11 & 51.2 & 56.1 & 60.0 & 2.64 & 0.013 & 0.177 & 0.488 \\
\hline & 15 & 54.8 & 61.5 & 59.5 & & & & \\
\hline \multirow[t]{2}{*}{$\mathrm{ADF}$} & 11 & 50.1 & 54.9 & 57.0 & 2.59 & 0.093 & 0.077 & 0.600 \\
\hline & 15 & 53.4 & 61.2 & 58.6 & & & & \\
\hline \multirow[t]{2}{*}{ Starch } & 11 & 97.8 & 97.9 & 97.2 & 1.15 & 0.817 & 0.012 & 0.700 \\
\hline & 15 & 96.4 & 97.2 & 95.8 & & & & \\
\hline
\end{tabular}

differences may have been the result of reduced DMI as GH increased. The decrease in DMI likely slowed passage rate, which would increase digestibility of the ration (Pino et al., 2018).

The digestibility of NDF increased with GH, but it did appear to plateau with the MGH treatment, evidenced by calves being offered MGH and HGH having similar NDF digestibility, whereas both were greater than LGH. These results align with the observed increase in NDF intake as GH inclusion increased, and are similar to those reported by Dennis et al. (2018) for similar-age calves. These authors reported linear increases in NDF digestibility as beet pulp was added to the diet from 0 to $30 \%$. Mitchell et al. (2020) also saw improvements in NDF digestibility when similar-age calves were converted from being component fed concentrate and GH to a $15 \%$ GH TMR, although calves in that study did not have different intakes of NDF.

The digestibility of ADF was affected similarly to NDF, except only tendencies were observed and ADF digestibility had an additional tendency to increase at 15 versus 11 wk. The increased ADF digestibility observed at $15 \mathrm{wk}$ may have been the result of a more favorable rumen environment for fiber digestion brought on by increased saliva production as the calves aged, which has been shown by others (Kay, 1960). In support of this, calves in this study had increased minimum and maximum rumen $\mathrm{pH}$ at $15 \mathrm{wk}$, and mean rumen $\mathrm{pH}$ numerically increased.

Starch digestibility decreased at 15 wk of age. This was likely an effect of increased passage rate brought on by increased DMI as calves aged. However, starch digestibility was still quite high and the decrease would not be expected to be biologically significant.

\section{Ruminal Fermentation}

Ruminal fermentation parameters are shown in Table 5. Interestingly, mean rumen $\mathrm{pH}$ and total VFA were not different between the treatments. Rumen $\mathrm{pH}$ and total VFA are expected to increase and decrease, respectively, with forage inclusion (Imani et al., 2017) due to forage reducing the amount of rapidly digestible nutrients in the diet and stimulating saliva production by increasing rumination (Nemati et al., 2015; Mirzaei et al., 2017). Figure $2 \mathrm{a}$ and $2 \mathrm{~b}$ show how rumen $\mathrm{pH}$ and total VFA changed over a 24 -h period. In evaluating rumen $\mathrm{pH}$ and total VFA over time, it is apparent that feeding behavior differed between calves offered LGH and those offered MGH and HGH. The rumen $\mathrm{pH}$ and total VFA of calves offered LGH was fairly static over the course of $24 \mathrm{~h}$, whereas MGH and HGH saw drastic decreases and increases in rumen $\mathrm{pH}$ and total VFA, respectively, immediately after feeding. The responses in rumen $\mathrm{pH}$ and total VFA for MGH and HGH are what would be expected from a large dose of highly digestible nutrients into the rumen. It was observed during the study that calves offered MGH and $\mathrm{HGH}$ would sort for concentrate and then eat grass hay throughout the remainder of the day, whereas those offered LGH would sort out the grass hay first and then slowly consume the concentrate throughout the day. It has been shown that increasing inclusion of long forage into diets increases how strongly calves will sort against the largest particles (Greter et al., 2008; Groen et al., 2015). Based on the observed interaction between diet and time for rumen $\mathrm{pH}$ and total VFA, it is apparent this is what occurred when calves were offered $>10 \% \mathrm{GH}$. The rumen $\mathrm{pH}$ for calves on LGH likely kept them from consuming large amounts of feed immediately after feed was offered in an attempt to keep their rumen $\mathrm{pH}$ stable. Gelsinger et al. (2020) observed similar feeding behavior when feeding a diet designed to induce ruminal acidosis and another designed to blunt ruminal acidosis. In their study, calves offered the blunt diet consumed the entire ration within $8 \mathrm{~h}$, whereas those offered the induced diet still had $50 \%$ of the offered ration remaining at the same time point. Figure $2 \mathrm{c}$ and $2 \mathrm{~d}$ show the interaction effects of age and time for rumen $\mathrm{pH}$ and total VFA, respectively. The reason for these observed interactions 
Table 5. Rumen pH and VFA profile of weaned dairy calves at 11 and 15 wk of age offered TMR containing 10\% (LGH), 17.5\% (MGH), or $25 \%$ grass hay $(\mathrm{HGH})$

\begin{tabular}{|c|c|c|c|c|c|c|c|c|}
\hline Item & $\begin{array}{l}\text { Age } \\
\text { (wk) }\end{array}$ & \multicolumn{3}{|c|}{ Diet } & $\mathrm{SE}$ & \multicolumn{3}{|c|}{$P$-value } \\
\hline \multirow[t]{2}{*}{ Mean } & 11 & 5.83 & 5.96 & 5.81 & 0.14 & 0.455 & 0.154 & 0.830 \\
\hline & 15 & 5.93 & 6.10 & 6.07 & & & & \\
\hline \multirow[t]{2}{*}{ Minimum } & 11 & $5.56^{\mathrm{a}}$ & $5.23^{\mathrm{ab}}$ & $4.80^{\mathrm{b}, \mathrm{y}}$ & 0.13 & 0.067 & 0.038 & 0.002 \\
\hline & 15 & 5.32 & 5.28 & $5.44^{\mathrm{x}}$ & & & & \\
\hline \multirow[t]{2}{*}{ Total VFA $(\mathrm{m} M)$} & 11 & 125.4 & 122.4 & 122.8 & 12.6 & 0.495 & 0.514 & 0.705 \\
\hline & 15 & 129.0 & 113.7 & 108.7 & & & & \\
\hline \multicolumn{9}{|l|}{ VFA $(\mathrm{mol} / 100 \mathrm{~mol})$} \\
\hline \multirow[t]{2}{*}{ Acetate } & 11 & 47.86 & 47.32 & 45.84 & 3.36 & 0.870 & 0.573 & 0.889 \\
\hline & 15 & 49.54 & 47.24 & 48.90 & & & & \\
\hline \multirow[t]{2}{*}{ Propionate } & 11 & 34.34 & 32.88 & 35.72 & 4.86 & 0.997 & 0.496 & 0.848 \\
\hline & 15 & 31.49 & 32.96 & 30.67 & & & & \\
\hline
\end{tabular}

${ }^{\mathrm{a}, \mathrm{b}}$ Means within a row with different superscripts differ at $P \leq 0.05$.

${ }^{\mathrm{x}, \mathrm{y}}$ Means within a column and variable with different superscripts differ at $P \leq 0.05$.
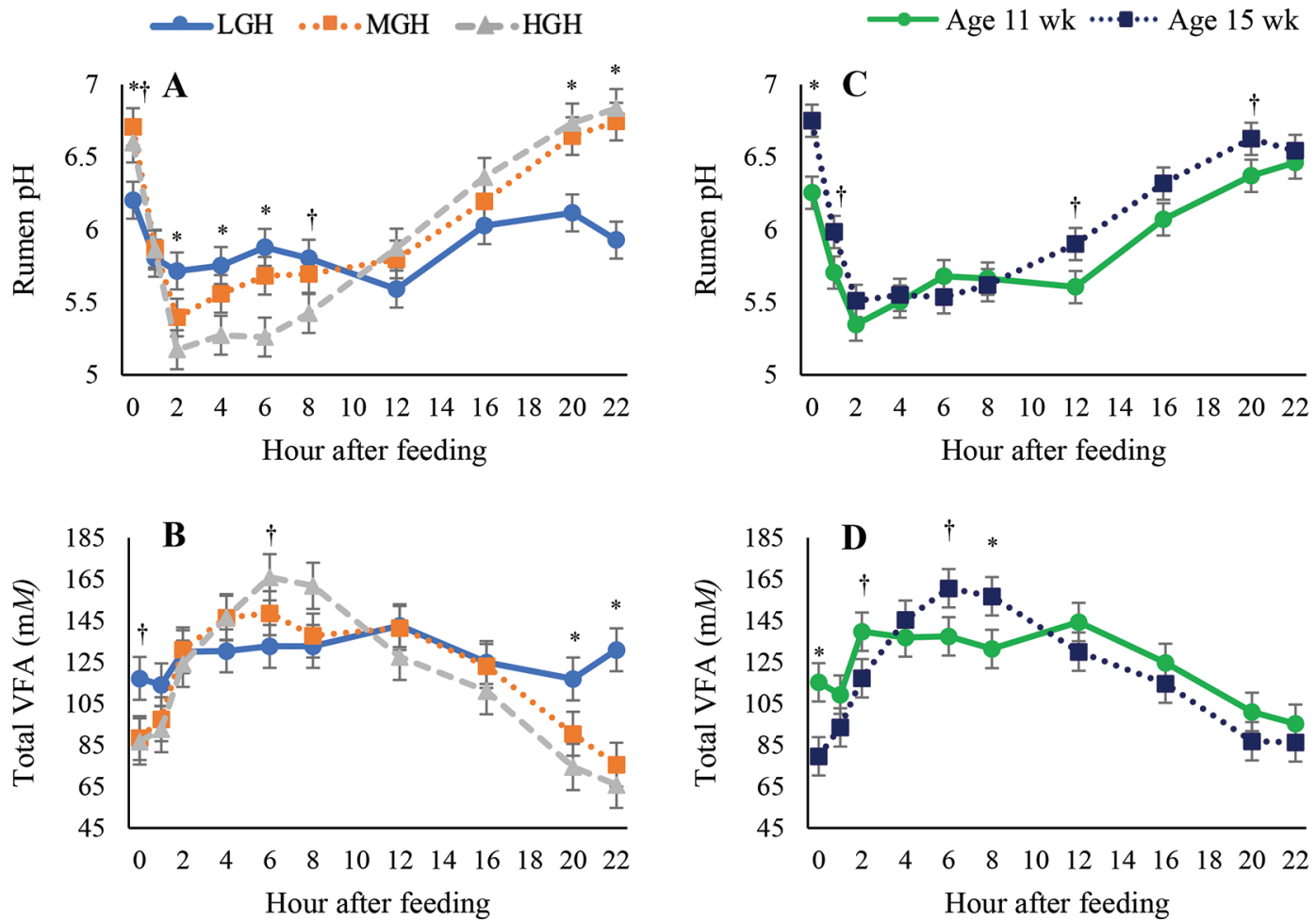

Figure 2. Rumen $\mathrm{pH}$ and total VFA concentration of rumen fluid over time of weaned dairy calves offered TMR containing $10 \%$ (LGH), $17.5 \%(\mathrm{MGH})$, or $25 \%$ grass hay (HGH) at 11 and $15 \mathrm{wk}$ of age. (A) Rumen pH of weaned dairy calves offered different amounts of grass hay over time. *Signifies differences between treatments at that time $(P \leq 0.05 ; 0 \mathrm{~h} \mathrm{LGH}<\mathrm{MGH} ; 2$ and $4 \mathrm{~h}$ HGH $<\mathrm{LGH} ; 6 \mathrm{~h}$ HGH $<$ LGH and MGH; 20 and $22 \mathrm{~h} \mathrm{LGH}<\mathrm{MGH}$ and HGH). †Signifies trends between treatments at that time $(0.05<P \leq 0.1 ; 0 \mathrm{~h} \mathrm{LGH}<\mathrm{HGH} ; 8 \mathrm{~h} \mathrm{HGH}$ $<$ LGH). (B) Rumen fluid total VFA concentration of weaned dairy calves offered different amounts of grass hay over time. *Signifies differences between treatments at that time $(P \leq 0.05 ; 20 \mathrm{~h} \mathrm{HGH}<\mathrm{LGH} ; 22 \mathrm{~h} \mathrm{MGH}$ and HGH $<\mathrm{LGH})$. †Signifies trends between treatments at that time $(0.05<P \leq 0.1 ; 0 \mathrm{~h} \mathrm{MGH}$ and $\mathrm{HGH}<\mathrm{LGH} ; 6 \mathrm{~h} \mathrm{LGH}<\mathrm{HGH})$. (C) Rumen pH of weaned dairy calves at 11 and 15 wk of age over time. *Signifies differences between treatments at that time $(P \leq 0.05)$. $\dagger$ Signifies trends between treatments at that time $(0.05<P \leq 0.1)$. (D) Rumen fluid total VFA concentration of weaned dairy calves at 11 and 15 wk of age over time. *Signifies differences between treatments at that time $(P \leq 0.05)$. $†$ Signifies trends between treatments at that time $(0.05<P \leq 0.1)$. Error bars represent \pm SE. 
is not readily apparent, though it may have been the result of differences in DMI and feeding behavior between calves at 11 and 15 wk of age.

The apparent feeding behavior differences between the treatments resulted in a decrease in minimum rumen $\mathrm{pH}$ as $\mathrm{GH}$ increased. This was especially clear at 11 wk when $\mathrm{HGH}$ had the lowest minimum rumen $\mathrm{pH}$ and LGH had the greatest. However, these differences did not persist at 15 wk resulting in a diet by age interaction. A similar diet by age interaction was observed for maximum rumen $\mathrm{pH}$, where HGH had the lowest maximum rumen $\mathrm{pH}$ at $11 \mathrm{wk}$ but the highest maximum rumen $\mathrm{pH}$ at $15 \mathrm{wk}$. It is possible that as calves aged saliva production increased (Kay, 1960), which is also supported by the increase in minimum and maximum $\mathrm{pH}$ from 11 to $15 \mathrm{wk}$.

Diet, age, and diet by age interaction had no effects on proportion of individual VFA or acetate to propionate ratio. Forage addition would be expected to increase the proportion of acetate and decrease
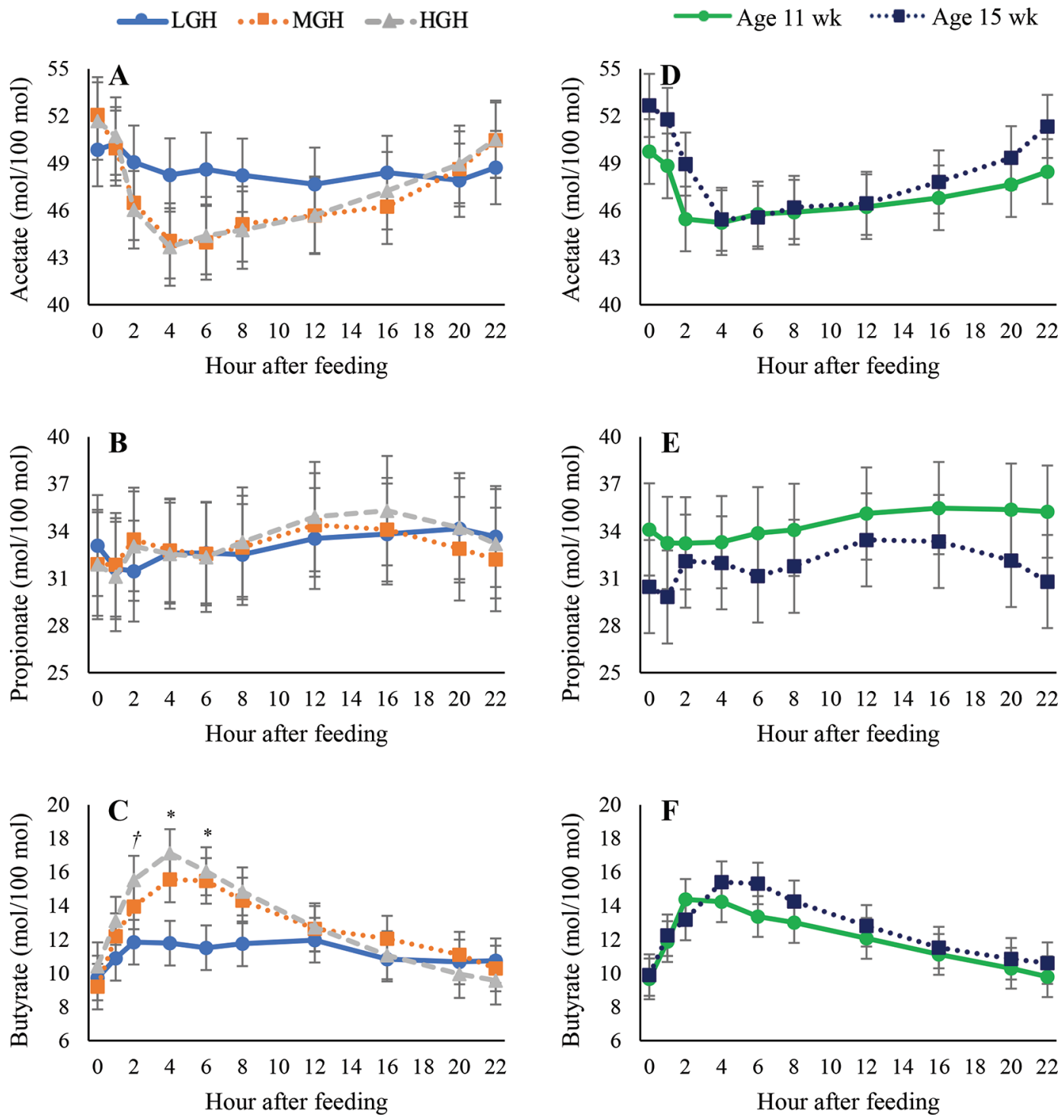

Figure 3. Individual VFA proportion in rumen fluid over time for weaned dairy calves offered TMR containing 10\% (LGH), 17.5\% (MGH), or $25 \%$ grass hay $(\mathrm{HGH})$ at 11 and $15 \mathrm{wk}$ of age. (A) Rumen acetate proportion for weaned dairy calves offered different amounts of grass hay over time. (B) Rumen propionate proportion for weaned dairy calves offered different amounts of grass hay over time. (C) Rumen butyrate proportion for weaned dairy calves offered different amounts of grass hay over time. *Signifies differences between treatments at that time $(P$ $\leq 0.05 ; 4$ and $6 \mathrm{~h} \mathrm{LGH}<\mathrm{MGH}$ and HGH). †Signifies trends between treatments at that time $(0.05<P \leq 0.1 ; 2 \mathrm{~h} \mathrm{LGH}<\mathrm{HGH})$. (D) Rumen acetate proportion for weaned dairy calves at 11 and $15 \mathrm{wk}$ of age over time. (E) Rumen propionate proportion for weaned dairy calves at 11 and 15 wk of age over time. (F) Rumen butyrate proportion for weaned dairy calves at 11 and 15 wk of age over time. Error bars represent \pm SE. 
the proportion of butyrate (Imani et al., 2017). It has also been observed in older heifers that increasing the amount of forage or decreasing starch content results in increased proportions of acetate and decreased proportions of propionate (Lascano and Heinrichs, 2009). The reason for a lack of observed differences in the current study may be due to the offered diets not having a large enough difference in starch content and in general containing very high amounts of starch, 50 to $40 \%$ for LGH to HGH. Figure 3 shows diet by time and age by time interactions for individual VFA. Diet by time did not have an interaction for propionate, but diet by time did have an interaction for acetate and butyrate. These observed interactions further support the idea that calves offered MGH and HGH had different feeding behavior than those offered LGH. The decrease in acetate and increase in butyrate proportions immediately after feeding for calves offered MGH and HGH are what would be expected from animals sorting for concentrate. Propionate and butyrate proportions also exhibited interaction effects between age and time. Propionate proportion was consistent over time at 11 wk, but it was reduced at $15 \mathrm{wk}$ and varied over time. Butyrate proportion peaked at $2 \mathrm{~h}$ at 11 wk but at $4 \mathrm{~h}$ at $15 \mathrm{wk}$.

\section{CONCLUSIONS}

Calves offered coarsely chopped GH, included at levels from 10 to $25 \%$ of DM, had reduced DM and ME intake. The reductions in intake led to decreases in ADG and EBWG that were especially pronounced in calves offered HGH. The growth difference resulted in a reduction in final BW with increasing $\mathrm{GH}$ inclusion. Despite the differences in final BW, no differences were observed in final skeletal frame measurements between the treatment groups. Fiber digestibility increased with increasing $\mathrm{GH}$, but increases between calves offered $\mathrm{MGH}$ and $\mathrm{HGH}$ were minimal. No differences were observed in mean rumen $\mathrm{pH}$ or total VFA. However, interactions between diet and time indicated that feeding behavior changed when calves were offered LGH versus MGH and $\mathrm{HGH}$, where those offered MGH and HGH sorted for concentrate immediately after feed was offered. This was further supported by a diet by time interaction observed for molar proportion of acetate and butyrate, which showed acetate decreasing and butyrate increasing immediately after diets were offered to calves consuming MGH and HGH. Based on these results, we conclude that feeding levels of $\mathrm{GH}$ $>10 \%$ will reduce intake and growth and alter ruminal fermentation in weaned dairy calves from 8 to $16 \mathrm{wk}$ of age.

\section{ACKNOWLEDGMENTS}

This research was a component of NC-2042; Management Systems to Improve the Economic and Environmental Sustainability of Dairy Enterprises, The Pennsylvania State University, University Park. The authors have not stated any conflicts of interest.

\section{REFERENCES}

Allen, M. S. 1996. Physical constraints on voluntary intake of forages by ruminants. J. Anim. Sci. 74:3063-3075. https://doi.org/10 $.2527 / 1996.74123063 x$

Allen, M. S. 2000. Effects of diet on short-term regulation of feed intake by lactating dairy cattle. J. Dairy Sci. 83:1598-1624. https:// doi.org/10.3168/jds.S0022-0302(00)75030-2.

AOAC International. 2000. Official Methods of Analysis. 17th ed. AOAC International, Gaithersburg, MD.

Aragona, K. M., F. X. Suarez-Mena, T. S. Dennis, J. D. Quigley, W. $\mathrm{Hu}$, T. M. Hill, and R. L. Schlotterbeck. 2020. Effect of starter form, starch concentration, and amount of forage fed on Holstein calf growth from 2 to 4 months of age. J. Dairy Sci. 103:2324-2332. https://doi.org/10.3168/jds.2019-17474.

Castells, L., A. Bach, G. Araujo, C. Montoro, and M. Terre. 2012. Effect of different forage sources on performance and feeding behavior of Holstein calves. J. Dairy Sci. 95:286-293. https://doi.org/10 .3168/jds.2011-4405.

Cumberland Valley Analytical Services. 2011. Procedure references. Accessed Mar. 12, 2020. https://www.foragelab.com/Media/ CVAS_Proceedure_References.pdf.

Davis, C. L., and J. K. Drackley. 1998. The Development, Nutrition, and Management of the Young Calf. Iowa State University Press, Ames.

Dennis, T. S., F. X. Suarez-Mena, T. M. Hill, J. D. Quigley, R. L. Schlotterbeck, and G. J. Lascano. 2018. Short communication: Effect of replacing corn with beet pulp in a high concentrate diet fed to weaned Holstein calves on diet digestibility and growth. J. Dairy Sci. 101:408-412. https://doi.org/10.3168/jds.2017-13292.

Gelsinger, S. L., W. K. Coblentz, G. I. Zanton, R. K. Ogden, and M. S. Akins. 2020. Physiological effects of starter-induced ruminal acidosis in calves before, during, and after weaning. J. Dairy Sci.103:2762-2772.

Greter, A. M., T. J. DeVries, and M. A. G. Von Keyserlingk. 2008. Nutrient intake and feeding behavior of growing dairy heifers: Effects of dietary dilution. J. Dairy Sci. 91:2786-2795. https://doi .org/10.3168/jds.2008-1052.

Groen, M. J., M. A. Steele, and T. J. DeVries. 2015. Effect of straw inclusion rate in a dry total mixed ration on the behavior of weaned dairy calves. J. Dairy Sci. 98:2693-2700. https://doi.org/10.3168/ jds.2014-8978.

Hall, M. B. 2009. Determination of starch, including maltooligosaccharides, in animal feeds: Comparison of methods and a method recommended for AOAC collaborative study. J. AOAC Int. 92:42-49. https://doi.org/10.1093/jaoac/92.1.42.

Heinrichs, A. J., C. M. Jones, S. M. Gray, P. A. Heinrichs, S. A. Cornelisse, and R. C. Goodling. 2013. Identifying efficient dairy heifer producers using production costs and data envelopment analysis. J. Dairy Sci. 96:7355-7362. https://doi.org/10.3168/jds.2012-6488.

Heinrichs, A. J., and W. C. Losinger. 1998. Growth of Holstein dairy heifers in the United States. J. Anim. Sci. 76:1254-1260. https:// doi.org/10.2527/1998.7651254x.

Hill, T. M., H. G. Bateman II, J. M. Aldrich, and R. L. Schlotterbeck. 2008. Effects of the amount of chopped hay or cottonseed hulls in a textured calf starter on young calf performance. J. Dairy Sci. 91:2684-2693. https://doi.org/10.3168/jds.2007-0935.

Hill, T. M., H. G. Bateman II, J. M. Aldrich, and R. L. Schlotterbeck. 2009. Roughage for diets fed to weaned dairy calves. Prof. Anim. Sci. 25:283-288. https://doi.org/10.15232/S1080-7446(15)30719-1. 
Hill, T. M., H. G. Bateman II, J. M. Aldrich, and R. L. Schlotterbeck. 2010. Roughage amount, source, and processing for diets fed to weaned dairy calves. Prof. Anim. Sci. 26:181-187. https://doi.org/ 10.15232/S1080-7446(15)30578-7.

Hoffman, P. C., K. A. Weigel, and R. M. Wernberg. 2008. Evaluation of equations to predict dry matter intake of dairy heifers. J. Dairy Sci. 91:3699-3709. https://doi.org/10.3168/jds.2007-0644.

Imani, M., M. Mirzaei, B. Baghbanzadeh-Nobari, and M. H. Ghaffari. 2017. Effects of forage provision to dairy calves on growth performance and rumen fermentation: A meta-analysis and metaregression. J. Dairy Sci. 100:1136-1150. https://doi.org/10.3168/ jds.2016-11561.

Jahn, E., and P. T. Chandler. 1976. Performance and nutrient requirements of calves fed varying percentages of protein and fiber. J. Anim. Sci. 42:724-735. https://doi.org/10.2527/jas1976.423724x.

Kay, R. N. B. 1960. The rate of flow and composition of various salivary secretions in sheep and calves. J. Physiol. 150:515-537. https: //doi.org/10.1113/jphysiol.1960.sp006402.

Lascano, G. J., and A. J. Heinrichs. 2009. Rumen fermentation pattern of dairy heifers fed restricted amounts of low, medium, and high concentrate diets without and with yeast culture. Livest. Sci. 124:48-57. https://doi.org/10.1016/j.livsci.2008.12.007.

Lascano, G. J., and A. J. Heinrichs. 2011. Effects of feeding different levels of dietary fiber through the addition of corn stover on nutrient utilization of dairy heifers precision-fed high and low concentrate diets. J. Dairy Sci. 94:3025-3036. https://doi.org/10.3168/ jds.2010-3831.

Lesmeister, K. E., and A. J. Heinrichs. 2004. Effects of corn processing on growth characteristics, rumen development, and rumen parameters in neonatal dairy calves. J. Dairy Sci. 87:3439-3450. https:// doi.org/10.3168/jds.S0022-0302(04)73479-7.

Mirzaei, M., M. Khorvash, G. R. Ghorbani, M. Kazemi-Bonchenari, and M. H. Ghaffari. 2017. Growth performance, feeding behavior, and selected blood metabolites of Holstein dairy calves fed restricted amounts of milk: No interactions between sources of finely ground grain and forage provision. J. Dairy Sci. 100:1086-1094. https://doi.org/10.3168/jds.2016-11592.

Mitchell, L. K., C. M. Jones, and A. J. Heinrichs. 2020. Effect of converting weaned dairy calves from a component-fed diet to a total mixed ration on growth and nutrient digestibility. J. Dairy Sci. 103:6190-6199. https://doi.org/10.3168/jds.2019-17980.

Mojahedi, S., M. Khorvash, G. R. Ghorbani, E. Ghasemi, M. Mirzaei, and F. Hashemzadeh-Cigari. 2018. Performance, nutritional behavior, and metabolic responses of calves supplemented with forage depend on starch fermentability. J. Dairy Sci. 101:7061-7072. https://doi.org/10.3168/jds.2017-13798.

Nemati, M., H. Amanlou, M. Khorvash, M. Mirzaei, B. Moshiri, and M. H. Ghaffari. 2016. Effect of different alfalfa hay levels on growth performance, rumen fermentation, and structural growth of Holstein dairy calves. J. Anim. Sci. 94:1141-1148. https://doi .org/10.2527/jas.2015-0111.

Nemati, M., H. Amanlou, M. Khorvash, B. Moshiri, M. Mirzaei, M. A. Khan, and M. H. Ghaffari. 2015. Rumen fermentation, blood metabolites, and growth performance of calves during transition from liquid to solid feed: Effects of dietary level and particle size of alfalfa hay. J. Dairy Sci. 98:7131-7141. https://doi.org/10.3168/ jds.2014-9144.

NRC. 2001. Nutrient Requirements of Dairy Cattle. 7th rev. ed. National Academy of Sciences Washington, DC.

Pino, F., L. K. Mitchell, C. M. Jones, and A. J. Heinrichs. 2018. Comparison of diet digestibility, rumen fermentation, rumen rate of passage, and feed efficiency in dairy heifers fed ad-libitum versus precision diets with low and high quality forages. J. Appl. Anim. Res. 46:1296-1306. https://doi.org/10.1080/09712119.2018 .1498788 .

Pritchard, R. H., and K. W. Bruns. 2003. Controlling variation in feed intake through bunk management1. J. Anim. Sci. 81:E133-E138. https://doi.org/10.2527/2003.8114_suppl_2E133x.

Qamar, Z. A., M. A. Rashid, T. N. Pasha, M. I. Malik, A. Saleem, M. Raza, H. U. Rehman, and M. S. Yousaf. 2019. Carryover effects of varying hay concentration on the transition to silage-based feeding of weaned dairy calves. S. Afr. J. Anim. Sci. 49:1028-1035.

Quigley, J. D., W. Hu, J. R. Knapp, T. S. Dennis, F. X. Suarez-Mena, and T. M. Hill. 2019. Estimates of calf starter energy affected by consumption of nutrients. 2. Effect of changing digestion on energy content in calf starters. J. Dairy Sci. 102:2242-2253. https://doi .org/10.3168/jds.2018-15354.

Stobo, I. J., J. H. Roy, and H. J. Gaston. 1966. Rumen development in the calf. Br. J. Nutr. 20:189-215. https://doi.org/10.1079/ BJN19660022.

Suarez-Mena, F. X., T. M. Hill, C. M. Jones, and A. J. Heinrichs. 2016. Review: Effect of forage provision on feed intake in dairy calves. Prof. Anim. Sci. 32:383-388. https://doi.org/10.15232/pas .2016-01502.

van Ackeren, C., H. Steingaß, K. Hartung, R. Funk, and W. Drochner. 2009. Effect of roughage level in a total mixed ration on feed intake, ruminal fermentation patterns and chewing activity of early-weaned calves with ad libitum access to grass hay. Anim. Feed Sci. Technol. 153:48-59. https://doi.org/10.1016/j.anifeedsci .2009.05.009.

Van Soest, P. J., J. Robertson, and B. Lewis. 1991. Methods for dietary fiber, neutral detergent fiber, and nonstarch polysaccharides in relation to animal nutrition. J. Dairy Sci. 74:3583-3597. https:/ /doi.org/10.3168/jds.S0022-0302(91)78551-2.

Weiss, W. P. 1998. Estimating the available energy content of feeds for dairy cattle. J. Dairy Sci. 81:830-839. https://doi.org/10.3168/jds .S0022-0302(98)75641-3.

Yang, C. M. J., and G. A. Varga. 1989. Effect of three concentrate feeding frequencies on rumen protozoa, rumen digesta kinetics, and milk yield in dairy cows. J. Dairy Sci. 72:950-957. https://doi .org/10.3168/jds.S0022-0302(89)79188-8.

Zanton, G. I., and A. J. Heinrichs. 2005. Meta-analysis to assess effect of prepubertal average daily gain of Holstein heifers on firstlactation production. J. Dairy Sci. 88:3860-3867. https://doi.org/ 10.3168/jds.S0022-0302(05)73071-X. 